
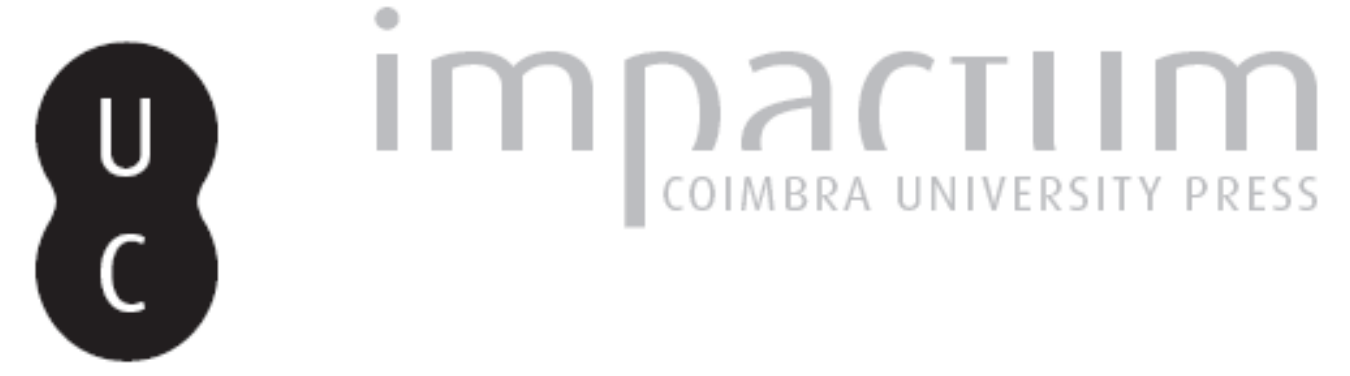

\title{
[Recensão a] VALLADARES, Rafael - La conquista de Lisboa. Violencia militar y comunidad politica en Portugal, 1578-1583
}

Autor(es): $\quad$ Paiva, José Pedro

Publicado por: Centro de História da Sociedade e da Cultura

URL persistente:

URI:http://hdl.handle.net/10316.2/39589

DOI:

DOI:http://dx.doi.org/10.14195/1645-2259_9_14

Accessed : $\quad$ 26-Apr-2023 03:06:23

A navegação consulta e descarregamento dos títulos inseridos nas Bibliotecas Digitais UC Digitalis, UC Pombalina e UC Impactum, pressupõem a aceitação plena e sem reservas dos Termos e Condições de Uso destas Bibliotecas Digitais, disponíveis em https://digitalis.uc.pt/pt-pt/termos.

Conforme exposto nos referidos Termos e Condições de Uso, o descarregamento de títulos de acesso restrito requer uma licença válida de autorização devendo o utilizador aceder ao(s) documento(s) a partir de um endereço de IP da instituição detentora da supramencionada licença.

Ao utilizador é apenas permitido o descarregamento para uso pessoal, pelo que o emprego do(s) título(s) descarregado(s) para outro fim, designadamente comercial, carece de autorização do respetivo autor ou editor da obra.

Na medida em que todas as obras da UC Digitalis se encontram protegidas pelo Código do Direito de Autor e Direitos Conexos e demais legislação aplicável, toda a cópia, parcial ou total, deste documento, nos casos em que é legalmente admitida, deverá conter ou fazer-se acompanhar por este aviso.

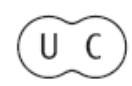



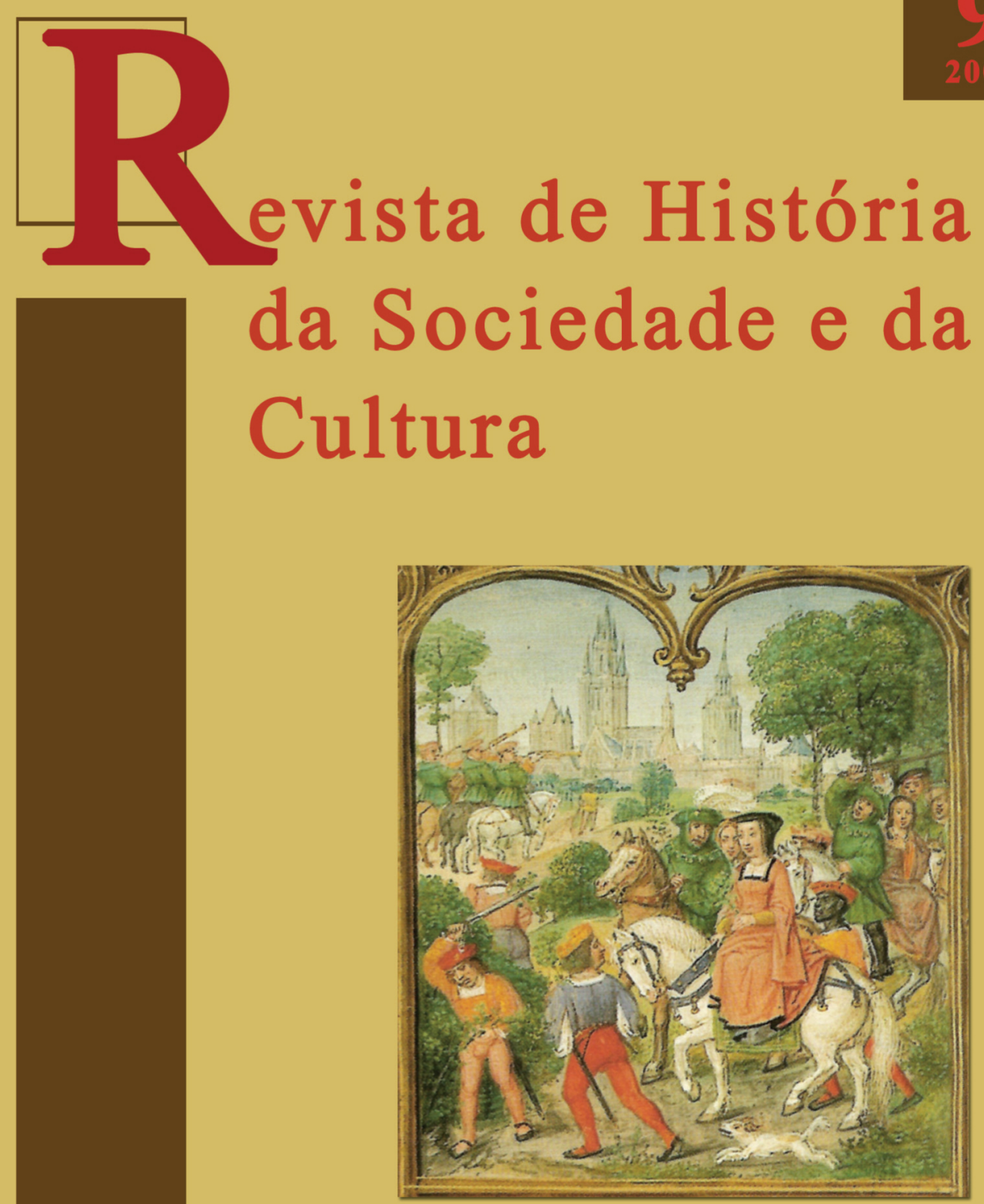

Centro de História da Sociedade e da Cultura Universidade de Coimbra

Coimbra 


\section{VALLADARES, Rafael - La conquista de Lisboa. Violencia militar y comunidad politica en Portugal, 1578-1583. Madrid: Marcial Pons, 2008, 315 p. e 3 ilustrações.}

O mais recente livro de Rafael Valladares, investigador do CSIC (Madrid), autor de sólida, bem informada e volumosa produção sobre o Portugal do tempo dos Áustria, é mais um precioso contributo para o conhecimento deste período. Espera-se, por isso, que em breve possa estar disponível em língua portuguesa, tal como sucede já com o seu $A$ independência de Portugal. Guerra e Restauração 1640-1680 (Lisboa: 2006).

Trata-se de estudo muito bem escrito, com uma estrutura interna clara e bem pensada, revelador de exímio e profundo domínio da bibliografia, mesmo a mais recente, e não só a espanhola. Aqui foram incorporados contributos da produção portuguesa, francesa, inglesa e italiana, que muito enriquecem as perspectivas do autor e conferem grande consistência ao resultado final. E não confinando este "apport" bibliográfico ao campo da História, pois abre o seu olhar, em doses equilibradas, à sociologia, à antropologia e à psicologia, no intuito de enquadrar melhor, em especial, a questão da violência. Com a vantagem de a bibliografia ser apresentada num elenco final, o que muito auxilia os leitores e se louva, tanto mais que, infelizmente, muitas editoras têm vindo a descartá-los dos seus livros, por razões exclusivamente economicistas. Os historiadores/autores não se de devem subjugar a isso.

Como Rafael Valladares confessa, o livro teve como detonador e ponto de partida um fresco por si observado no Palácio Spinola, em Génova, o qual é pouco considerado pela historiografia do Portugal hispânico. Trata-se de "Lisboa assediada pelo exército do Duque de Alba", pintado por Lazzaro Tavarone, entre 1614 e 1615, aqui reproduzido a preto e branco e com pouca qualidade (p. 4). Não justificaria melhor reprodução?

A partir dele, e do olhar instigador do autor, a sua proposta é clara e encontra-se explicitada logo na Apresentação, o que, de certo modo antecipa e esvazia a expectactiva do leitor. O livro promove três "ideias", ou teses: 1 - o sucedido em Portugal entre 1578 e 1583 foi, para além de uma crise dinástica, uma "guerra civil"; 2 - a violência militar exercida pelas forças filipinas, foi imprescindível no processo de agregação/conquista do novo 
reino e teve um impacto muito maior do que tem sido habitualmente reconhecido pela historiografia; 3 - O conceito chave para entender o fundo do problema, isto é, o modo como os portugueses se comportaram neste processo, é o de "comunidade", "entendida esta como uma soma de todas as instâncias corporativas num reino composto por vassalos de diferente condição jurídica, no entanto unidos por valores morais e afectivos, como o amor à pátria, a reunião em torno de uma fé, a lealdade às leis, e o apego à tradição" (p. 18). Explicitação que podia ser formulada com mais rigor. O amor à pátria, a identificação com um território e com o seu rei, uma consciência histórica mínima de um passado comum, o reconhecimento de certos símbolos como agregadores, a utilização da mesma língua, a noção de que havia inimigos externos da comunidade (castelhanos - o que é reconhecido por Valladares na p. 47 -, piratas, muçulmanos, etc.), eram igualmente elementos fundamentais do sentido de "comunidade", que não podem ser apenas enunciados como "valores morais e afectivos". Eram isso, mas eram, no século XVI, já e também muito mais do que isso.

Retomando a tese principal, o objectivo fundamental do livro é o de recuperar a dimensão violenta da guerra de conquista de Portugal por Castela, entre Junho de 1580 (saque do Palácio dos Duques de Bragança, em Vila Viçosa) e 3 de Agosto de 1583 (conquista de Angra, nos Açores, pela armada chefiada por Santa Cruz). Recuperar a dimensão violenta da guerra e apurar o impacto que ela teve no corpo político de um reino que, em teoria, estaria a salvo, em função das negociações mantidas com os estamento sociais privilegiados e com as mais importantes instituições (p. 27).

Mas, no fundo, parece poder entender-se, sobretudo quando se chega ao final e se lê o Epílogo, que uma das intenções do autor foi igualmente proceder a uma revisão historiográfica das condições da agregação de Portugal à monarquia hispânica, tendo em mira, eu diria sobretudo, questionar a tese ultimamente praticamente indiscutida, principalmente entre os historiadores espanhóis, de que aquela união resultou, acima de tudo, de um processo de negociação política laboriosamente preparado pelos agentes filipinos enviados a Portugal desde 1578, e consumada nesse acto política e simbolicamente decisivo que teriam sido as cortes de Tomar de 1581 . Em suma, o "pacto de Tomar", acto fundador do "Portugal dos Felipes", como lhe chamou Fernando Bouza Alvarez, o principal defensor e hodierno 
baluarte desta proposta. Creio que, embora isso nunca seja clarificado abertamente por Valladares, apesar de aqui e ali ser sugerido (p. 31 e 37, por exemplo) este seu livro é também (e muito) um diálogo/debate com as perspectivas de Fernando Bouza. Apesar de no referido Epílogo, se recordar que esta ideia da negociação política já tinha um grande lastro no tempo, que Valladares encontra bem enunciada pela primeira vez numa obra de 1628 (Manuel Faria e Sousa - Epitome de las historias portuguesas) a qual, como o autor sublinha, visava enaltecer o papel dos Moura, ao tempo marqueses de Castelo Rodrigo, herdeiros do já falecido e decisivo personagem na tal negociação que fora Cristóvão de Moura (p. 277).

Antes de explicitar a estrutura e conteúdo do livro, diga-se que o título parece ser uma metáfora, onde, como se percebe após a leitura da obra, sobretudo da sua primeira parte, "Lisboa" está por "Portugal". Aliás, da conquista de Lisboa propriamente dita, tanto da batalha terrestre em Alcântara, a 25 de Agosto, como da naval na barra do Tejo (o "abraço anfíbio" de que fala o autor), pouco se diz. O que se entende, pois o livro não pretende ser um estudo de História Militar, de uma certa História Militar clássica, sobretudo a que foi escrita por militares, mas antes uma análise de história política, de boa história política, sempre atenta à minuciosa reconstituição dos acontecimentos, intenções e estratégias dos seus agentes nas circunstâncias concretas em que os tiveram que enfrentar.

O livro está estruturado em duas partes. A primeira, intitulada "Violência", trata da guerra e da sua importância decisiva para a agregação do Reino. É composta por um "Preâmbulo" e cinco bem escolhidos capítulos, todos servidos por claros e sugestivos títulos: 1 - A escolha de Alba; 2 - As leis da guerra; 3 - O assalto a Lisboa; 4 - "Não pensei que eram tantos" (frase escrita por Felipe II referindo-se à sensação de que nunca imaginara que os partidários de D. António fossem tão numerosos) 5 - "Acabar com isto desta vez" (Açores).

A segunda, designa-se "Comunidade" e engloba outros cinco capítulos: 1 - A cidade antes da conquista; 2 - Os desejos do rei; 3 - "Matar-se-ão entre eles" (Guerra civil); 4 - A comunidade abandonada; 5 - A rebelião popular. Por fim o já referido Epílogo, com o explícito título "A lenda do triunfo negociado". 
Não me deterei no rico conteúdo de cada capítulo, onde a par de dados conhecidos se descobrem outros que são novos. Relevarei, tão só, algumas das informações/ideias neles sugeridas, aqui e ali entrecruzadas por um olhar crítico.

Para principiar esta restrita selecção, a verificação de que a correspondência que D. Felipe II manteve com os seus comandos militares e com os embaixadores (nomeadamente com Cristóvão de Moura e Juan da Silva) tinha um tom diferente (p. 44), sendo que alguma violência verbal dominou as ordens que foram dadas sobre a guerra antes que ela se efectuasse, o que teria servido de estímulo à criação de um certo clima de tensão (p. 76). A guerra/invasão propriamente dita começa a ser dissecada pelo capítulo 2 . A partir dos exemplos do sucedido em Olivença, Elvas e Mourão mostra-se como no decurso de todo o processo de incorporação do Reino houve uma utilização simultânea de violência (ou a sua ameaça) e negociação política com as forças locais, evidenciando, no entanto, que a coacção exercida pelo poder bélico dos exércitos castelhanos não deixava margem de manobra. Para os habitantes de Mourão, por exemplo, confrontados com um exército de 700 soldados inimigos "a saída consistiu em vestir de obediência uma espécie de rendição" (p. 81).

Os actos de violência, para além do já referido saque de Vila Viçosa (p. 85-86), começaram, sobretudo, quando o exército castelhano encontrou resistência. E o primeiro local onde isso sucedeu foi em Setúbal, onde, como diz e bem o autor, pela primeira vez se constatou como tinha sido irrealista supor que a intervenção do exército filipino constituiria um passeio triunfal, no qual se iria "coleccionando a obediência de todos os lugares do reino" (p. 87). De novo em Cascais se impuseram severos castigos sobre os conquistados, com a execução tanto do comandante das tropas portuguesas como do alcaide. É certo que houve ordens para conter a violência e o saque, o que levou a que o duque de Alba tivesse inclusivamente executado soldados seus, por terem, como era usual e se esperava em tempos de guerra, saqueado Setúbal, tentando assim dissuadir e limitar os excessos destas operações. Temia-se que elas se pudessem repetir em Lisboa, o que teria, naturalmente, consequências terríveis para a imagem de D. Felipe II aos olhos dos portugueses. 
Da batalha de Alcântara se salienta como durou poucas horas da manhã de 25 de Agosto de 1580, mas que fez 500 a 3000 mortos entre os apoiantes do Prior do Crato (p. 98). Analisou-se o saque que se seguiu e que durou 3 dias, com os efeitos negativos que teve sobre a população da cidade, mas sobretudo nos seus arrabaldes. Depois surge o que o autor designou por "segunda conquista de Portugal", a qual se prolongou entre Setembro e Novembro de 1580, e visou impor a obediência a Castela nas regiões situadas a Norte do Tejo, bem como, se possível, capturar o fugitivo D. António. Neste processo, os exércitos chefiados por Sancho Dávila depararam-se com uma resistência passiva e surda por todo o País (Aveiro seria excepção), no fundo encontraram uma população que não estava disposta a colaborar com os invasores (p. 117). O autor procura explicá-lo não como o resultado de um "patriotismo natural das gentes", mas antes pelos prejuízos causados nas suas vidas e na actividade económica (p. 118). Esta é uma interpretação, que não está sequer abonada documentalmente, o que é pena. Não pode deixar de se lembrar, que a Restauração, 60 anos depois, também causou muitos sacrifícios nas vidas e na economia das gentes, mas então elas estiveram dispostas a aceitar, sem grande resistência conhecida, esses mesmos sacrifícios. Igualmente se estranha que na análise da "segunda conquista" não se citem ou utilizem alguns estudos que contemplam dados importantes para perceber o que se passou em determinados dos locais que se iam submetendo. Como é o caso de Coimbra, para onde não há nenhuma referência ao importante trabalho de Mário Brandão - Coimbra e D. António rei de Portugal (Coimbra: 1939-1947, 3 volumes). Por estas páginas se reflecte ainda no que se deveria fazer ao Prior do Crato, caso viesse a ser encontrado: matá-lo, onde e como? ou exilá-lo em Castela? (p. 122). A questão é ainda bem aproveitada para revelar as fracturas internas entre castelhanos, salientando a existência de duas facções: uma a dos "políticos", o "círculo de Badajoz", favoráveis a uma solução negocial, e outra a dos militares, os quais tiveram que intervir pela força para impor o que a negociação política não estava a conseguir, facção encabeçada pelo Duque de Alba e Sancho Dávila, cujas posições ficam bem evidentes num excelente trecho de uma carta que este escreveu, e que o autor, e bem, aqui transcreveu (p. 124-125). Este capítulo 4, pelos assuntos e perspectivas abordados assume-se como um momento chave na estrutura da obra e na 
demonstração de algumas das suas teses. A propaganda filipina, de que é expressão bem evidente a obra de Conestaggio - Historia dell'Unione del Regno di Portogallo alla corona di Castiglia (1585), bem procurou insistir na ideia de que Portugal não fora "conquistado", mas "unido" e de que os muitos opositores a essa união ("não pensei que fossem tantos", chegou a escrever D. Felipe II) não eram por isso "rebeldes", mas apenas "vassalos inquietos difíceis de sujeitar ao novo jugo" (p. 138). Aqui fica bem evidente que não foi assim. Nem mesmo depois da conquista, pois como se dirá mais adiante, já na segunda parte, as tropas de Castela jamais abandonaram totalmente Lisboa, que ficou sempre "presidiada", ou, como diz o autor: "a sombra da conquista voltava a cobrir as luzes da negociação" (p. 177).

A segunda parte da obra não me parece tão bem conseguida como a primeira. Se bem li, afigura-se-me que aqui se pretenderam alcançar dois objectivos distintos. Por um lado, descrever/caracterizar a comunidade - neste caso Lisboa e não Portugal - sobretudo nas vésperas e antevésperas da sua conquista. Por outro, mostrar como é que uma parte maioritária dessa comunidade (isto é, os populares ou "povo"), se comportou perante os acontecimentos e os programas de conquista/aliciamento, que tanto D. Felipe II como o Prior do Crato sobre eles exerceram (uma boa ideia, por vezes esquecida, pois D. António também teve estratégias para ganhar adeptos).

O resultado final não foi tão convincente como o alcançado na primeira parte do livro, basicamente, por quatro ordens de razões:

1) Porque há uma série de incursões, por vezes longas, sobre assuntos que não se conseguiram articular com explícito proveito com a questão nevrálgica do livro, como é o caso da incursão pelo governo de D. Sebastião, as pestes que assolaram Lisboa desde os anos 60 ou o papel das mulheres na vida da cidade. Detenho-me só no caso do governo do Desejado. É esse o centro do capítulo 7, que tem por título "os desejos do rei”, que, ao contrário do que se poderia pensar, não é D. Felipe II, mas antes D. Sebastião. O capítulo fecha-se numa análise interpretativa do que foi o seu governo, com propostas discutíveis e até especulativas. Dois exemplos. Parece-me discutível a tese de que quando em 1568 o jovem rei assume o poder tivesse como programa "a construção de uma imagem de magestade real" que restaurasse a autoridade do poder régio, dilacerada por disputas que enquistavam o centro político 
no período anterior das regências (p. 181). Discutível e até contraditório, pois, no parágrafo imediato a esta proposta de chave interpretativa, Valladares constata: "Declarado mayor de edad a los catorce anos, era muy improbable que mostrase entonces ninguna idea de gobierno". Parece-me especulativa e não compaginável com o discurso histórico a sugestão (que funciona como argumento para justificar que o projecto da guerra em Marrocos não era um devaneio), de que se D. Sebastião tivesse triunfado em Alcácer isso teria tido como resultado a subjugação de certas facções cortesãs a submeterem-se à autoridade do rei.

2) Porque as razões encontradas para explicar o posicionamento da comunidade de Lisboa face aos episódios da conjuntura de 1580 não me pareceram muito convincentes e não beneficiaram de algumas das análises encetadas. Por exemplo, parece-me pouco útil discutir o conceito de "guerra civil" (cap. 8), sendo certo terem existido fracturas evidentes entre portugueses, que os colocaram, em armas, de diferentes lados da "guerra". Tal como não se afigura convincente a explicação de que os populares aderiram maioritariamente a $\mathrm{D}$. António não por razões positivas, mas antes como reacção a uma situação de desencontro e descontentamento com o rei e com aqueles que os deveriam ter protegido: "Ni el amor a don Antonio, ni a Portugal, ni siquiera el fogoso anticastellanismo fueran la causa mayor que permitió a los seguidores del prior reclutar al vulgo, sino el malestar, el resentimiento y la decepcion que éste abrigaba hacia sus siperiores por su dejacion de deberes" (p. 246).

3) Porque o caminho analítico aqui proposto sugere que Portugal era apenas um conjunto de comunidades, de que Lisboa, "a princesa" seria a mais emblemática e importante. Dessa lógica decorrem dois factores que objectivamente dificultam a interpretação de fundo sobre os sucessos de 1580. Primeiro de que só através do estudo de todas as outras comunidades (Braga, Lamego, Arronches, Tavira, etc.) será possível obter uma visão global e definitiva do assunto, caminho, no limite, inviável. Segundo, e mais preocupante, supor que Portugal, enquanto tal, não era também uma comunidade. Nesse sentido, alguns jogos de palavras, sem dúvida de belo efeito retórico, mais do que elucidar confundem. “(...) lo que latía en las reiteradas y fogosas llamadas a la historia del reino y a la nación portuguesa era una suerte de patriotismo comunitario en vez de nacionalismo patriotico, en la 
medida en que la comunidad importaba más que la nacion (...)” (p. 230, itálico meu). Seria assim? Como prová-lo? E a "nação" (não a oitocentista evidentemente) não era uma comunidade?

Terceito, porque a análise empreendida não contribuíu para entender melhor os efeitos que a conquista pela guerra teve na tal "comunidade", e isso também era expectável nesta obra e um dos objectivos a que o autor se propôs.

Uma nota final sobre as fontes. Valladares utilizou sobretudo as castelhanas, ou seja, as legadas pelos vencedores, que conhece e domina com profundidade, diria até, com erudição. Não haveria outras que abrissem uma janela para perceber melhor e observar os vencidos, e assim, justificar a sua própria tese de que os efeitos da guerra, da violência da guerra, tiveram consequências muito mais gravosas do que por norma se considera?

Um ou outro pequeno lapso não perturbam a qualidade do estudo, mas poderiam corrigir-se. Por exemplo: sugere-se que em 1580 Portugal teria apenas cerca de 1 milhão de habitantes (p. 71), o que não é exacto; não há em Portugal nenhuma localidade com o nome Nabão (p. 177); o Conselho Geral do Santo Ofício não foi apenas criado em 1570 (p. 184), já existia praticamente desde os primórdios da existência do Tribunal; o conflito entre D. Henrique e D. João de Portugal, bispo da Guarda, não durou até 1585 (p. 202), data em que o cardeal já tinham falecido e o bispo sido privado do bispado; ao contrário do que se afirma, a Inquisição portuguesa nunca teve jurisdição sobre adultério, nem perseguiu adúlteros (p. 247).

Pesem as notas críticas aqui deixadas, que também devem ser tomadas como um exercício, este é, em suma, um livro que muito se recomenda e que será muito útil, até pelo seu tom didáctico, a todos os alunos universitários de História. Eu sugerirei a sua leitura aos meus.

\section{José Pedro Paiva}

Universidade de Coimbra e Centro de História da Sociedade e da Cultura da UC. lejpaiva@fl.uc.pt 